\title{
Hekim Dışı Acil Sağlık Hizmetleri Çalışanlarına Verilen Acil Obstetrik Bakım Eğitiminin Etkinliğinin Değerlendirilmesi: Ön Test Son Test Araştırma
}

\section{Evaluation of the Effectiveness of Emergency Obstetric Care Training Given to Non-Physician Emergency Health Care Personnel: Pre-Test Post-Test Study}

\author{
Yeter Şener $^{1}$ (iD) Evrim Bayraktar ${ }^{2}$ \\ ${ }^{1}$ Yozgat Bozok Üniversitesi Sağllk Bilimleri Fakültesi, Yozgat, TÜRKIYE \\ ${ }^{2}$ Erciyes Üniversitesi Sağlık Bilimleri Fakültesi, Kayseri, TÜRKIYE \\ Geliş tarihi/ Date of receipt: 26/09/2020 Kabul tarihi/ Date of acceptance: 09/01/2021 \\ (C) Ordu University Faculty of Health Sciences, Department of Nursing, Turkey, Published online: 18/04/202
}

ÖZ

Amaç: $\mathrm{Bu}$ araştırma hekim dışı acil sağlık hizmetleri çalışanlarına verilen Acil Obstetrik Bakım (AOB) eğitiminin etkinliğinin değerlendirilmesi amaciyla yapıldı.

Yöntem: Ön test son test yarı deneysel desende gerçekleştirildi. Araştırmanın örneklemini 30 hekim dışı acil sağlık hizmetleri çalışanı oluşturdu. Verilerin değerlendirilmesinde McNemar testi kullanıldı.

Bulgular: Hekim dış1 acil sağlık hizmetleri çalışanlarının eğitim öncesine göre eğitim sonrasında AOB bilgi sorularını doğru cevaplama oranlarında istatistiksel olarak anlamlı düzeyde artış olduğu saptandı $(p<0.05)$.

Sonuç: Hekim dışı acil sağlık hizmetleri çalışanlarının anne ve bebek ölümlerinin azaltılması amacıyla AOB konusunda bilgi düzeylerini güncellemeye yönelik hizmet içi eğitimlerle desteklenmeleri önerilir.

Anahtar kelimeler: Acil obstetrik bakım, sağlık çalışanları, eğitim

\section{ABSTRACT}

Objective: The purpose of this study was to evaluate the effectiveness of Emergency Obstetric Care (EOC) training given to nonphysician emergency healthcare personnel.

Methods: The pre-tests post-tests were carried out in a semi-experimental pattern. The study sample consisted of 30 non-physician emergency healthcare workers. McNemar test was used in evaluating the data.

Results: It has been found out that there was a statistically meaningful increase in the rates of correct answers to EOC knowledge questions by non-physician emergency healthcare personnel following the training, in comparison with prior to the training.

Conclusion: Supporting non-physician emergency healthcare personnel with on the job training courses is recommended to update their level of knowledge on EOC in order to reduce mother and infant deaths $(\mathrm{p}<0.05)$.

Keywords: Emergency obstetric care, healthcare personnel, education

ORCID IDs of the authors: YŞ: 0000-0002-8919-4395; EB: 0000-0002-2914-197X

Sorumlu yazar/Corresponding author: Öğr. Gör. Yeter Sener

Yozgat Bozok Üniversitesi, Sağlı Bilimleri Fakültesi, Yozgat, TÜRKIYE

e-posta/e-mail: hem_yetersener@hotmail.com

Attf/Citation: Şener Y, Bayraktar E. (2021). Hekim dışı acil sağlık hizmetleri çalışanlarına verilen acil obstetrik bakım eğitiminin etkinliğinin

değerlendirilmesi: ön test son test araştırma. Ordu Üniversitesi Hemşirelik Çalışmaları Dergisi, 4(1), 75-82. DOI: 10.38108/ouhcd.800632 


\section{Giriş}

Dünya genelinde anne ve yenidoğan ölüm ve sakatlanmalarının azaltılması amacı sürdürülebilir kalkınma hedefleri içerisinde öncelikli olmaya devam etmektedir (WHO 2015). Çoğu anne/yenidoğan ölümleri ve ölü doğumlar doğum sirasında veya doğumdan hemen sonra ortaya çıkmaktadır (Ameh ve ark., 2019). Gebelik ve doğumla ilgili sorunlar, dünya çapında günde 830 annenin ölümüne neden olmaktadır (WHO 2018). Türkiye'de ise, anne ölüm oranı 100.000 canlı doğumda 13.6'dır (TÜİK 2020). Birçok anne ölümü, gebelikte, doğum sırasında ve doğumdan hemen sonra şiddetli kanama, enfeksiyonlar, gebelikte hipertansif bozukluklar, doğum komplikasyonları gibi önlenebilir nedenlerle meydana gelmektedir (Devine ve Taylor, 2018).

Dünya Sağlık Örgütü (DSÖ), obstetrik komplikasyonların önlenmesi ile anne ve yenidoğan ölümlerinin azaltılmasında Acil obstetrik bakımın (AOB) önemli bir yeri olduğunu vurgulamaktadır (WHO 2016). AOB gebelik, doğum ve doğumdan sonraki ilk 42 gün içerisinde oluşan, anne ve bebek hayatını tehdit eden, acil müdahale yapılması gereken durumlarda verilen hizmetlerin bütünü olarak tanımlanmaktadır. AOB hizmetlerinin iyileştirilmesi için sağlık kuruluşlarının yeterli araç ve gereçler ile donatılması, süratli müdahale edilmesi ve sağlık çalışanlarının konu ile ilgili bilgi ve hazır bulunuşluğunun arttırılması gerekmektedir (T.C. Sağlık Bakanlığı 2007). Yapılan araştırmalarda verilen AOB eğitimlerinin sağllk çalışanlarının bilgi seviyelerinde iyileştirmeler sağladığ1 ve verilen bakımın kalitesini artırdığ1 bildirilmektedir (Ameh ve ark., 2012; Moran ve ark., 2015; Partamin ve ark., 2012; Van Lonkhuijzen ve ark., 2010). Anne ve fetüs sağlığının korunması, komplikasyonların, ölüm ve sakatlanmaların önlenmesi için sağlık hizmetleri çalışanlarının AOB ile ilgili bilgi düzeylerinin yeterli olması gerekmektedir (T.C. Sağlık Bakanlığı 2007).

Yapılan literatür taramasında Türkiye'de hekim dışı acil sağlık hizmetleri çalışanlarının AOB'a ilişkin bilgi düzeylerini belirleyen ve bilgi eksikliklerini gidermeye yönelik bir araştırmaya rastlanmamıștır. Bu araştırma hekim dıșı acil sağlık hizmetleri çalışanlarına verilen AOB eğitiminin etkinliğinin değerlendirilmesi amacıyla yapıldı.

\section{Gereç ve Yöntem}

\section{Araştırmanın tipi}

Araştırma ön test-son test tek gruplu yarı deneysel bir araştırmadır.

\section{Araştırmanın yapıldı̆̆ı yer}

Araştırma Türkiye'de bulunan bir ilçede yer alan bir hastanenin acil servisinde ve 112 acil çağrı merkezinde yapıld1.

\section{Araştırmanın evreni ve örneklemi}

Araştırma 01.04.2017-11.04.2017 tarihleri arasında yürütüldü. Araştırmanın evrenini bir ilçede bulunan hastanenin acil servis ve 112 acil çağrı merkezinde çalışan hekim dışı acil sağlık hizmetleri çalışanları oluşturdu. Araştırmada örneklem seçimine gidilmedi. Araştırmanın yapıldı̆̆ tarihlerde acil serviste ve 112 acil çağrı merkezinde çalışan tüm hekim dişı acil sağlık hizmetleri çalışanları ( $\mathrm{n}=30)$ örneklem kapsamına alındı.

\section{Verileri toplama araçları}

Araștırmada verilerin toplanmasında Tanitıcı Özellikler Formu ve AOB Soru Formu kullanıldı.

Tanıtıcı Özellikler Formu; tanitıcı ve AOB ile ilgili özellikleri içeren (yaş, cinsiyet, AOB'la ilgili yayın/dergi takip etme durumu, vs.) sorulardan oluşturuldu.

Acil Obstetrik Bakım Soru Formu; literatür (T.C. Sağlık Bakanlığ1, 2009; Van den Broek, 2014; Coutin, 2015) ve 5 uzman görüşü doğrultusunda hekim dışı acil sağlık hizmetleri çalışanlarının AOB'nin tanımı ve kapsamı, AOB ile ilgili doğum öncesi, sırası ve sonrası doğru cevaplama oranını belirleyen 4 bölümden ve çoktan seçmeli beş şıklı tek doğru cevabı olan 34 sorudan olușturuldu. $\mathrm{Bu}$ anket ölçeklendirme veya puanlama sistemi olarak kullanılmadi.

\section{Acil Obstetrik Bakım Eğitimi}

Araştırmacılar tarafından literatür (T.C. Sağllk Bakanlığı, 2009; Van den Broek, 2014; Coutin, 2015) ve 5 uzman görüşü doğrultusunda eğitim planı ve broşürü hazırlandı. Eğitim broşürü hekim dışı acil servis ve 112 acil çağrı merkezi çalışanlarına tanıtıcı özellikler ve AOB soru formu ön testinin uygulanmasından sonra aynı gün bir hafta boyunca incelemeleri için verildi. Eğitim planı ve broşürü obstetrik acil durumlarda gerekli temel bilgi ve becerilerin yanı sıra acil servise başvuru yapılan ya da 112 acil çağrı merkezinin aranmasına neden olan obstetrik aciller ve bu acillere müdahalede kullanılacak uygun girişimleri içerecek șekilde tasarlandı. Eğitimin içeriğinde; AOB tanımı, kapsamı ve obstetrik acilleri çözme yaklaşımı konuları yer aldı. Acil serviste görev alan hekim dış1 acil sağlık hizmetleri çalışanları acil servisin çalışma düzeninin etkilenmemesi açısından iki grup şeklinde öğleden önce ve sonra olacak şekilde eğitim odasında toplanıldı. Eğitim planına ve broşürüne uygun bir şekilde eğitim sunum şeklinde 
gerçekleştirildi. Eğitim sırasında soru-cevap, vaka analizi, beyin fırtınası ve tartışma yöntemleri kullanıldı. Eğitim sunumu 45-60 dk. sürdü. Sunumdan sonra hekim dişı acil sağlık hizmetleri çalışanlarının bütün soruları cevaplandırıldı. Bütün sorulara yanit verildikten sonra uygun geri bildirimle birlikte eğitim sonlandırıldı ve eğitimden hemen sonra AOB Soru Formu son testi uyguland. 112 acil çağrı merkezinde ise eğitimin aynısı ve yapılan işlemler ertesi gün tekrarland1.

\section{Verilerin toplanması}

Tanıtıc1 Özellikler Formu ve AOB Soru Formunun ön testi eğitim gruplarında aynı gün uyguland1. AOB Soru Formunun son testi hekim dış1 acil servis çalışanlarına eğitimden hemen sonra aynı gün, hekim dışı 112 acil çağrı merkezi çalışanlarına ise ertesi gün eğitim verildikten hemen sonra uygulanılarak toplanıldı. Hekim dışı acil sağlık hizmetleri çalışanlarının birbirinden etkilenmesinin önlenmesi açısından; formların doldurulması araştırmacı gözetiminde gerçekleştirildi ve oturma düzenine dikkat edildi.

\section{Verilerin değerlendirilmesi}

Veriler IBM SPSS 22.0 (IBM Corp., Armonk, New York, ABD) paket programında değerlendirildi. Eğitim öncesi ve sonras1 karşılaştırmalar McNemar testi ile gerçekleştirildi. $p<0.05$ değeri istatistiksel olarak anlamlı kabul edildi.

\section{Bulgular}

Araştırmaya katılan hekim dışı acil sağlık hizmetleri çalışanlarının \%63.3'ünün kadın ve \%63.4'ünün 21-30 yaş grubunda, \%53.3'ünün ön lisans, \%23.3'ünün ise lisans mezunu olduğu saptand1. Çalışanların \%53.3'ünün hemşire ve ebeden oluştuğu, \%60'ının meslekte görev yapma süresinin 6 yıl ve üzeri, \%90'ının bu kurumda görev yapma süresinin ve \%70'inin acil servis/112 acil çağrı merkezinde çalışma süresinin 0-6 yıl olduğu belirlendi (Tablo 1).

Tablo 1. Hekim dışı acil sağlık hizmetleri çalışanlarının tanıtıcı özelliklerinin dağılımı $(\mathrm{N}=30)$

\begin{tabular}{|c|c|c|}
\hline Tanıtıcı Özellikler & Sayı $(n)$ & Yüzde $(\%)$ \\
\hline \multicolumn{3}{|l|}{ Cinsiyet } \\
\hline Kadın & 19 & 63.3 \\
\hline Erkek & 11 & 36.7 \\
\hline \multicolumn{3}{|l|}{ Yaș Grubu } \\
\hline $21-30$ & 19 & 63.4 \\
\hline $31-40$ & 7 & 23.3 \\
\hline $41>$ & 4 & 13.3 \\
\hline Yaş Ortalama $(\mathrm{x} \pm \mathbf{s d})$ & \multicolumn{2}{|c|}{$29.7 \pm 7.2$} \\
\hline \multicolumn{3}{|l|}{ Eğitim Durumu } \\
\hline Sağlık Meslek Lisesi & 5 & 16.7 \\
\hline Ön lisans & 16 & 53.3 \\
\hline Lisans & 7 & 23.3 \\
\hline Yüksek Lisans & 2 & 6.7 \\
\hline \multicolumn{3}{|l|}{ Meslek } \\
\hline Hemsire & 9 & 30.0 \\
\hline Ebe & 7 & 23.3 \\
\hline ATT & 6 & 20.0 \\
\hline Paramedik & 5 & 16.7 \\
\hline Anestezi Teknisyeni & 3 & 10.0 \\
\hline \multicolumn{3}{|c|}{ Bu meslekte görev yapma süresi } \\
\hline $0-6$ y1l & 12 & 40.0 \\
\hline 6 yil ve üzeri & 18 & 60.0 \\
\hline \multicolumn{3}{|c|}{ Bu kurumda görev yapma süresi } \\
\hline $0-6$ y1l & 27 & 90.0 \\
\hline 6 yıl ve üzeri & 3 & 10.0 \\
\hline \multicolumn{3}{|c|}{ Acil servis/112 acil çağrı merkezinde çalışma süresi } \\
\hline $0-6$ y1l & 21 & 70.0 \\
\hline 6 yil ve üzeri & 9 & 30.0 \\
\hline Toplam & 30 & 100.0 \\
\hline
\end{tabular}


Hekim dışı acil sağlık hizmetleri çalışanlarının $\% 100.0$ 'ünün kurum içi düzenli eğitim almadığ $\% 56.7$ 'sinin daha önce $\mathrm{AOB}$ eğitimi almadı $\breve{g}_{1}$, daha önce AOB eğitimi alanların \%61.5'inin AOB'a yönelik sertifikasının olduğu, \%76.7'sinin son bir ayda obstetrik acillerle 2-5 kez karşılaştığ belirlendi. Çalıșanların \%100.0'ünün obstetrik acillere müdahalede sorun yaşamadığ $1, \% 56.7$ 'sinin kendini AOB ekibi içerisinde hissettiği, \%36.7'sinin obstetrik acillere müdahalede kendini yeterli bulduğu, \%96.7'sinin ise AOB ile ilgili yayın/dergi takip etmediği saptandı (Tablo 2).

Tablo 2. Hekim dışı acil sağlık hizmetleri çalışanlarının AOB ile ilgili özelliklerinin dağılımı $(\mathrm{N}=30)$

\begin{tabular}{|c|c|c|}
\hline Özellikler & Sayı (n) & Yüzde (\%) \\
\hline \multicolumn{3}{|c|}{$\begin{array}{l}\text { Kurum içi düzenli eğitim alma } \\
\text { durumu }\end{array}$} \\
\hline Evet & - & - \\
\hline Hayır & 30 & 100 \\
\hline \multicolumn{3}{|c|}{$\begin{array}{l}\text { Daha önce AOB eğitimi alma } \\
\text { durumları }\end{array}$} \\
\hline Alan & 13 & 43.3 \\
\hline Almayan & 17 & 56.7 \\
\hline \multicolumn{3}{|c|}{$\begin{array}{l}\text { AOB'a yönelik sertifikası } \\
\text { olma durumu }(n=13)\end{array}$} \\
\hline Var & 8 & 61.5 \\
\hline Yok & 5 & 38.5 \\
\hline \multicolumn{3}{|c|}{$\begin{array}{l}\text { Son bir ayda obstetrik } \\
\text { acillerle karşılaşma durumu }\end{array}$} \\
\hline $0-1 \mathrm{kez}$ & 6 & 20.0 \\
\hline $2-5 \mathrm{kez}$ & 23 & 76.7 \\
\hline $6-9 \mathrm{kez}$ & 1 & 3.3 \\
\hline \multicolumn{3}{|c|}{$\begin{array}{l}\text { Obstetrik acillere müdahalede } \\
\text { sorun yaşama durumu }\end{array}$} \\
\hline Yaşayan & - & - \\
\hline Yaşamayan & 30 & 100.0 \\
\hline \multicolumn{3}{|c|}{$\begin{array}{l}\text { Kendini AOB ekibi içerisinde } \\
\text { hissetme durumu }\end{array}$} \\
\hline Evet & 17 & 56.7 \\
\hline Hayır & 7 & 23.3 \\
\hline Emin değil & 6 & 20.0 \\
\hline \multicolumn{3}{|c|}{$\begin{array}{l}\text { Obstetrik acillere müdahalede } \\
\text { kendini yeterli bulma durumu }\end{array}$} \\
\hline Yeterli & 11 & 36.7 \\
\hline Yetersiz & 10 & 33.3 \\
\hline Emin değil & 9 & 30.0 \\
\hline \multicolumn{3}{|c|}{$\begin{array}{l}\text { AOB ile ilgili yayın/dergi } \\
\text { takip etme durumu }\end{array}$} \\
\hline Takip eden & 1 & 3.3 \\
\hline Takip etmeyen & 29 & 96.7 \\
\hline
\end{tabular}

Hekim dışı acil sağlık hizmetleri çalışanlarının AOB' 'n tanımı ve kapsamı, doğum öncesi, doğum sıras1, doğum sonrası dönemde gelişebilecek ve AOB gerektiren durumlara ilişkin soruları doğru cevaplama oranlarının eğitim sonrasında daha yüksek olduğu tespit edildi. Amacını açıklayabilme ve amniyotik siv1 embolisini belirleyebilme sorularına verilen cevaplar dışında aralarında istatistiksel olarak anlamlı bir fark olduğu belirlendi ( $p<0.05$; Tablo 3).

\section{Tartışma}

$\mathrm{Bu}$ araştırma hekim dışı acil sağlı hizmetleri çalışanlarına verilen $\mathrm{AOB}$ eğitiminin etkinliğinin değerlendirilmesi amaciyla gerçekleştirildi. $\mathrm{Bu}$ araştırmada hekim dışı acil sağlık hizmetleri çalışanlarının tamamının AOB ile ilgili kurum içi düzenli eğitim almadığ daha önce AOB eğitimi almadığ önce eğitim alanların yarısından fazlasının AOB'a yönelik sertifikası olduğu tespit edildi. Dörtte üçünden fazlasının son bir ayda obstetrik acillerle 25 kez karşılaştığı, tamamının obstetrik acillere müdahalede sorun yaşamadığı saptandı. Yarısından fazlasının kendini AOB ekibi içerisinde hissettiği, üçte birinden fazlasının obstetrik acillere müdahalede kendini yeterli bulduğu, tamamına yakınının ise AOB ile ilgili yayın/dergi takip etmediği belirlendi (Tablo 2). Hekim dışı acil sağlık hizmetleri çalışanlarının eğitim öncesi AOB'nin tanımı, kapsamı, doğum öncesi, sırası ve sonrasına ilişkin soruları doğru cevaplama oranlarının düşük olduğu saptandı (Tablo 3). Çalışanlarda obstetrik acillere müdahalede kendilerini yeterli bulanların ve müdahalede sorun yaşamadığını ifade edenlerin AOB eğitimi öncesi doğru cevaplama oranlarının düşük olduğu gözlemlendi. Bunun nedeninin acil servise gelen hastaların yeterli kapasitede kadın doğum/ yoğun bakım servisleri ya da yeterli sayıda kadın hastalıkları ve doğum uzmanının olmamasından kaynaklı hızlı bir şekilde sevk edilmiş olabilecekleri düşünüldü. Bununla beraber sevk sırasında müdahale gerektirecek herhangi bir durumun yaşanmamış olmasından da kaynaklanmış olabileceği düşünüldü. Çalışanların çoğunluğunun obstetrik acillerle karşılaşmasına rağmen AOB eğitimi öncesi doğru cevaplama oranlarının düşük olmas1 obstetrik acillerin, zamanında müdahale edilememesi ve sevk sirasinda gecikmeler yaşanmasına neden olabilmesi bakımından önemlidir. Çalışanlar arasında daha önce AOB eğitimi aldığını belirten ve alanlarında çoğunluğunun sertifikası olduğunu ifade etmesine rağmen doğru cevaplama oranlarının düşük olduğu gözlemlendi. Araştırmanın bu bulgusu hizmet içi 
eğitimlerin belirli aralıklarla tekrarlanması gereğini göstermektedir. Mirkuzie ve arkadaşlarının (2014) Etiyopya'da temel acil obstetrik ve yenidoğan bakım hizmetleri halk sağlığı merkezlerinde yaptıkları araştırmalarında son beş yılda sağlık çalışanlarının konu ile ilgili bilgi ve yetkinliklerinin belirlenmesinde hizmet içi AOB eğitimi alıp almadıkları sorgulanmaktadır. $\mathrm{Bu}$ araştırma kapsamında 2008 yılında 25 çalışandan dördünün ve 2013 y1lında 24 çalışandan sadece üçünün eğitim aldığı ve bilgi/yetkinlik olarak aralarında fark olmadığı bildirilmektedir (Mirkuzie ve ark., 2014). Yapılan bu araştırma sonucu da aradan belirli bir zaman geçtikten sonra sağlık çalışanlarının konu ile ilgili bilgi ve yetkinliklerinin belirlenmesi yönüyle aralarında fark olmadığının bildirilmesi, bu nedenle hizmet içi eğitimlerin belirli aralıklarla tekrarlanması gereğini göstermesi yönüyle araştırma sonucunu destekler niteliktedir. Okonofua ve arkadaşlarının (2019) Nijerya'daki sağlık personellerinin AOB konusundaki bilgi ve becerilerinin değerlendirildiği araştırmasında sağlık personellerinin AOB hakkında bilgi ve becerilerinin ortalamanın altında olduğu bildirilmektedir (Okonofua ve ark., 2019).

Tablo 3. Acil obstetrik bakım eğitimi öncesi ve sonrası doğru cevaplama oranlarının dağılımı $(\mathrm{N}=30)$

\begin{tabular}{|c|c|c|c|c|c|}
\hline \multirow{4}{*}{ Özellikler } & \multicolumn{4}{|c|}{ AOB bilgi düzeyi } & \multirow{4}{*}{$p$} \\
\hline & \multirow{2}{*}{\multicolumn{2}{|c|}{\begin{tabular}{c|} 
Ön test \\
Doğru
\end{tabular}}} & \multirow{2}{*}{\multicolumn{2}{|c|}{$\begin{array}{c}\text { Son test } \\
\text { Doğru }\end{array}$}} & \\
\hline & & & & & \\
\hline & n & $(\%)$ & $\mathbf{n}$ & $(\%)$ & \\
\hline \multicolumn{6}{|l|}{ AOB tanım ve kapsamı } \\
\hline Tanımını yapabilme & 11 & 36.7 & 28 & 93.3 & $<0.001$ \\
\hline Amacını açıklayabilme & 23 & 76.7 & 28 & 93.3 & 0.063 \\
\hline Üç gecikme modelini belirleyebilme & 6 & 20.0 & 25 & 83.3 & $<0.001$ \\
\hline Sevk gerekmeyen koşulu belirleyebilme & 10 & 33.3 & 26 & 86.7 & $<0.001$ \\
\hline Kan nakli gerekmeyen koşulu belirleyebilme & 20 & 66.7 & 29 & 96.7 & 0.004 \\
\hline \multicolumn{6}{|l|}{ Doğum öncesi dönemde gelişebilecek ve AOB gerektiren durumlar } \\
\hline Fetal distres için uygun olmayan girişimi belirleyebilme & 15 & 50.0 & 28 & 93.3 & $<0.001$ \\
\hline Gün aşımı gebelik bulgusunu belirleyebilme & 12 & 40.0 & 27 & 90.0 & $<0.001$ \\
\hline Preeklampsi tanısını belirleyebilme & 22 & 73.3 & 30 & 100.0 & - \\
\hline Eklampsi tanısını belirleyebilme & 24 & 80.0 & 30 & 100.0 & - \\
\hline Ciddi kronik anemi bulgusunu belirleyebilme & 25 & 83.3 & 30 & 100.0 & - \\
\hline Dehidratasyon tanısını belirleyebilme & 26 & 86.7 & 30 & 100.0 & - \\
\hline Dış gebelik olmayan durumu belirleyebilme & 9 & 30.0 & 26 & 86.7 & $<0.001$ \\
\hline Molar gebelik olmayan durumu belirleyebilme & 14 & 46.7 & 28 & 93.4 & $<0.001$ \\
\hline Plasenta previa olmayan durumu belirleyebilme & 12 & 40.0 & 26 & 86.7 & $<0.001$ \\
\hline Yüksek ateş durumunda gerekli girişimi belirleyebilme & 15 & 50.0 & 27 & 90.0 & 0.002 \\
\hline Fetal ölüm olmayan durumu belirleyebilme & 1 & 3.3 & 23 & 76.7 & $<0.001$ \\
\hline Düşük tehdidi durumunda gerekli girişimi belirleyebilme & 6 & 20.0 & 28 & 93.3 & $<0.001$ \\
\hline Sepsis durumunda gerekli girişimi belirleyebilme & 7 & 23.3 & 23 & 76.7 & $<0.001$ \\
\hline Akut batın için uygun olmayan girişimi belirleyebilme & 21 & 70.0 & 30 & 100.0 & - \\
\hline Batın içi travma için uygun olmayan girişimi belirleyebilme & 17 & 56.7 & 30 & 100.0 & - \\
\hline Amniyotik s1v1 embolisini belirleyebilme & 23 & 76.7 & 28 & 93.4 & 0.063 \\
\hline Eklamptik konvülsiyonlar için uygun girişimi belirleyebilme & 7 & 23.3 & 26 & 86.7 & $<0.001$ \\
\hline Şiddetli preeklampside uygun olmayan girişimi belirleyebilme & 16 & 53.3 & 28 & 93.3 & $<0.001$ \\
\hline Fetal hareket/kalp sesi yokluğunda gerekli girişimi belirleyebilme & 22 & 73.3 & 28 & 93.3 & 0.031 \\
\hline $\begin{array}{l}\text { Servikal os dilate/aktif kanama olması durumunda uygun olmayan girişimi } \\
\text { belirleyebilme }\end{array}$ & 7 & 23.3 & 23 & 76.7 & $<0.001$ \\
\hline Hızlı değerlendirme koşulunu belirleyebilme & 12 & 40.0 & 23 & 76.7 & 0.003 \\
\hline \multicolumn{6}{|l|}{ Doğum sırasında gelişebilecek ve AOB gerektiren durumlar } \\
\hline Anormal doğum komplikasyonunu belirleyebilme & 22 & 73.3 & 30 & 100.0 & - \\
\hline Uterus rüptürü belirtisini belirleyebilme & 16 & 53.3 & 30 & 100.0 & - \\
\hline $\begin{array}{l}\text { Doğum eylemi başladığı/kaçınılmazlığ } \text { durumunda uygun olmayan } \\
\text { girişimi belirleyebilme }\end{array}$ & 27 & 90.0 & 30 & 100.0 & - \\
\hline
\end{tabular}


Tablo 3. (Devam) Acil obstetrik bakım eğitimi öncesi ve sonrası doğru cevaplama oranlarının dağılımı $(\mathrm{N}=30)$

\begin{tabular}{|c|c|c|c|c|c|}
\hline \multicolumn{6}{|l|}{ Doğum sonrası dönemde gelişebilecek ve AOB gerektiren durumlar } \\
\hline Postpartum hemorajinin nedeni olmayan koşulu belirleyebilme & 13 & 43.3 & 27 & 90.0 & $<0.001$ \\
\hline Doğum sonrası aktif kanama durumunda uygun girişimi belirleyebilme & 15 & 50.0 & 29 & 96.7 & $<0.001$ \\
\hline $\begin{array}{l}\text { Enfeksiyon açısından antibiyotik tedavisi gerektirmeyen koşulu } \\
\text { belirleyebilme }\end{array}$ & 15 & 50.0 & 30 & 100.0 & - \\
\hline Düşük sonrası yönetimde uygun olmayan girişimi belirleyebilme & 6 & 20.0 & 23 & 76.7 & $<0.001$ \\
\hline Postpartum kanama durumunda uygun olmayan girişimi belirleyebilme & 11 & 36.7 & 28 & 93.3 & $<0.001$ \\
\hline
\end{tabular}

Puri ve arkadaşlarının (2012) Bugesera Bölgesi'nde yapılan obstetrik bakım veren sağlık çalışanlarının güvenli annelik bakımı konusundaki bilgi, tutum ve uygulamaları ile ilgili araştırmasında, sağlık çalışanlarının sorulan soruların yarısından azını doğru cevapladığı bildirilmektedir. Aynı araştırmada sağlık çalışanlarının en zayıf alanlarının obstetrik komplikasyonlar ve normal doğum eylemi olduğu ve bu konuda bilgi düzeylerinin düşük olduğu belirtilmektedir. Sağlık çalışanlarının bu değerlerden dolayı AOB konusunda geliştirilmeleri gerektiği ifade edilmektedir (Puri ve ark., 2012). Bu bulgular bu araştırmanın bulguları ile benzerlik göstermektedir.

$\mathrm{Bu}$ araştırmada hekim dıșı acil sağlık hizmetleri çalışanlarının AOB'nın tanımı, kapsamı, doğum öncesi, sırası ve sonrasına ilişkin soruların eğitim sonrasında doğru cevaplama oranlarının daha yüksek olduğu bulundu (Tablo 3). Verilen eğitimin yapılan değerlendirmeler sonucunda etkili olduğu kararı verildi. Ameh ve arkadaşlarının (2016) Sahraaltı Afrika ve Asya'da acil obstetrik ve erken yenidoğan bakımında yeterlilik bazlı sağlık çalışanlarının eğitim öncesi ve sonrası bilgi ve becerilerini konu alan araştırmasında sağlık çalışanlarının acil obstetrik ve yenidoğan bakımına ilişkin bilgi ve becerilerinin geliştirilmesinde eğitimin etkili olduğu bildirilmektedir (Ameh ve ark., 2016). Itote Wanjugu ve arkadaşlarının (2019) Kenya'nın kırsalındaki obstetrik bakım veren sağlık çalışanlarının intrapartum bakım bilgisini araştırdıkları araştırmalarında, sağlık çalışanlarının toplam ortalama bilgi puanlarının düşük olduğu belirtilmektedir. $\mathrm{Bu}$ durumun sağlık çalışanlarına verilen eğitim firsatları ile obstetrik bakımın kalitesinin artırılabileceği ve anne sağlı̆̆ için Sürdürülebilir Kalkınma Hedefleri hedefine ulaşma yolunda ilerlemeyi sağlayabileceği belirtilmektedir (Itote Wanjugu ve ark., 2019). Diğer bazı yapılan araştırmalarda ise sağlık çalışanlarının genel olarak bilgi puanlarının temel obstetrik bakımda yetkinliği göstermek için gereken kabul edilebilir seviyenin oldukça altında olduğu bildirilmektedir. Sağlık çalışanlarının AOB için önerilerini doğru bir şekilde belirleseler bile sürekli olarak kanıta dayalı bakım sağlayamadıkları belirtilmektedir. AOB eğitiminin sağlık çalışanlarının AOB konusundaki bilgi ve uygulamalarını geliştirdiği ifade edilmektedir (Ameh ve Van den Broek, 2015; Green ve ark., 2015). Bu bulgular bu araştırmanın bulguları ile benzerlik göstermektedir.

\section{Sonuç ve Öneriler}

$\mathrm{Bu}$ araştırmada hekim dışı acil sağlık hizmetleri çalışanlarının eğitim öncesine göre eğitim sonrasında AOB bilgi sorularını doğru cevaplama oranlarında istatistiksel olarak anlamlı düzeyde artış olduğu saptandı. Çalışılan alana özgü yapılan eğitimlerin, sağlık çalışanlarının bilgi düzeyini artırdığı ve farkındalık sağladığı söylenebilir.

AOB'da kaliteli ve güvenilir hizmet verilebilmesi için sağlık çalışanlarının hizmet içi eğitimlerle bilgilerinin belirli zaman aralıklarla güncellenmesi, verilen eğitim içeriğinin $\mathrm{s} 1 \mathrm{k}$ karşılaşılan komplikasyonlar, bakım, tedavi ve müdahale gibi konuları içermesi önerilmektedir. Bunların yanı sıra verilen eğitimlerin simülasyon uygulamaları şeklinde oluşturulması ve örneklem büyüklüğünün artırılarak benzer araştırmaların yapılması önerilmektedir.

\section{Araştırmanın Sınırlılıkları}

Araştırmanın acil serviste ve 112 acil çağrı merkezinde çalışan hekim dışı acil sağlık hizmetleri çalışanları ile yapılması nedeniyle anketlerin uygulanması ve toplu olarak eğitim verilmesi için zaman bulunmasında güçlük yaşandı. Bu nedenle eğitimden önce ve sonra uygulanan anket formlarının toplanmasi gruplar halinde gerçekleştirildi. 
Araştırmanın Etik Yönü/ Ethics Committee Approval: Araştırmaya başlamadan önce araştırmanın yapıldığı kurum ve etik kuruldan (Karar No:2017/66, Tarih: 03.02.2017) gerekli izinler alındı. Anketler uygulanmadan önce hekim dişı acil sağlık hizmetleri çalışanlarına araştırmanın amacı ve elde edilen verilerin bilimsel amaçlı kullanılacağına dair gerekli açıklamalar yapılarak Bilgilendirilmiş Gönüllü Oluru alındı.

Hakem/Peer-review: Dış hakem değerlendirmesi.

Yazar Katkısı/Author Contributions: Fikir/kavram: YŞ, EB; Tasarım: YŞ, EB; Danışmanlık: EB; Veri toplama: YŞ; Veri işleme: YŞ; Analiz ve/veya Yorum YŞ, EB; Kaynak tarama: YŞ; Makalenin Yazımı: YŞ, EB; Eleştirel inceleme: YŞ, EB.

Çıkar çatışması/Conflict of interest: Herhangi bir çıkar çatışması yoktur.

Finansal Destek/Financial Disclosure: $\mathrm{Bu}$ çalışma herhangi bir kurum yada kuruluş tarafından desteklenmemiştir.

\section{Çalışma Literatüre Ne Kattı?}

- Hekim dışı acil sağlık hizmetleri çalışanlarının acil obstetrik bakım konusundaki bilgi düzeylerinin belirlenmesi yönüyle literatüre katkıda bulunulmuştur.

- Hekim dışı acil sağlık hizmetleri çalışanlarının acil obstetrik bakım konusundaki görüşleri bu alanda yapılacak olan araştırmalara kaynak oluşturmuştur.

\section{Kaynaklar}

Ameh CA, Mdegela M, White S, Van den Broek N. (2019). The effectiveness of training in emergency obstetric care: A systematic literature review. Health Policy and Planning, 34(4), 257-270. DOI: 10.1093/heapol/czz028.

Ameh C, Adegoke A, Hofman J, Ismail FM, Ahmed FM, Van den Broek N. (2012). The impact of emergency obstetric care training in Somaliland, Somalia. International Journal of Gynecology \& Obstetrics, 117(3), 283-287. DOI: $10.1016 /$ j.ijgo.2012.01.015.

Ameh CA, Kerr R, Madaj B, Mdegela M, Kana T, Jones $S$ ve ark. (2016). Knowledge and skills of healthcare providers in Sub-Saharan Africa and Asia before and after competency-based training in emergency obstetric and early newborn care. PLoS One, 11(12), e0167270. https://doi.org/10.1371/journal.pone.0167270.

Ameh CA, Van den Broek N. (2015). Making it happen: Training health-care providers in emergency obstetric and newborn care. Best Practice \& Research Clinical Obstetrics \& Gynaecology, 29(8), 1077-1091. DOI: 10.1016/j.bpobgyn.2015.03.019.
Okonofua F, Ntoimo LFC, Ogu R, Galadanci H, Gana M, Adetoye D ve ark. (2019). Assessing the knowledge and skills on emergency obstetric care among health providers: Implications for health systems strengthening in Nigeria. PLoS One, 14(4), e0213719. DOI: 10.1371/journal.pone.0213719.

Coutin AS. (2015). Essential Obstetric and Newborn Care: Practical Guide for Midwives, Doctors with Obstetrics Training and Health Care Personnel who Deal with Obstetric Emergencies. Médecins Sans Frontières, p. 17-243. ISBN 2-906498-98-X.

Devine S, Taylor G. (2018). Every child alive: The urgent need to end newborn deaths. United Nations Children's Fund (UNICEF), 1-22.

Green M, Rider C, Ratcliff D, Woodring BC. (2015). Developing a systematic approach to obstetric emergencies. Journal of Obstetric, Gynecologic \& Neonatal Nursing, 44(5), 677-682. DOI: 10.1111/1552-6909.12729.

Itote Wanjugu E, Fleming LC, Mallinson RK, Gaffney KF, Jacobsen KH. (2019). Knowledge of intrapartum care among obstetric care providers in rural Kenya, International Health, 11(4), 258-264. DOI:10.1093/inthealth/ihy078.

Mirkuzie AH, Sisay MM, Reta AT, Bedane MM. (2014). Current evidence on basic emergency obstetric and newborn care services in Addis Ababa, Ethiopia; A cross sectional study. BMC Pregnancy and Childbirth, 14, 354. DOI: 10.1186/1471-239314-354.

Moran NF, Naidoo M, Moodley J. (2015). Reducing maternal mortality on a countrywide scale: The role of emergency obstetric training. Best Practice \& Research Clinical Obstetrics \& Gynaecology, 29(8), 1102-1118. DOI: 10.1016/j.bpobgyn.2015.08.002.

Partamin, Kim YM, Mungia J, Faqir M, Ansari N, Evans C. (2012). Patterns in training, knowledge, and performance of skilled birth attendants providing emergency obstetric and newborn care in Afghanistan. International Journal of Gynecology \& Obstetrics, 119(2), 125-129. DOI: 10.1016/j.ijgo.2012.05.030.

Puri R, Rulisa S, Joharifard S, Wilkinson J, Kyamanywa P, Thielman N. (2012). Knowledge, attitudes, and practices in safe motherhood care among obstetric providers in Bugesera, Rwanda. International Journal of Gynaecology and Obstetrics, 116(2), 124-127. DOI: 10.1016/j.ijgo.2011.09.025.

TC. Sağlık Bakanlığı Ana Çocuk Sağlığı ve Aile Planlaması Genel Müdürlüğü. (2009). Acil Obstetrik Bakım Yönetim Rehberi, Ankara, Damla Matbaacilık, s. 7-61.

TC. Sağlık Bakanlığı Ana Çocuk Sağlığı ve Aile Planlaması Genel Müdürlüğü. (2007). Türkiye Üreme Sağlığı Programı No: 3-A. Acil Obstetrik Bakım Klinisyen Eğitimi Katılımcı Rehberi, Ankara, s. 3-130. ISBN 978-975-590-211-1. 
TÜİK (2020). Sürdürülebilir Kalkınma Göstergeleri, 2010-2018, Sayı: 33847, Erişim tarihi:06.07.2020, https://tuikweb.tuik.gov.tr/PreHaberBultenleri.do?i $\mathrm{d}=33847$

Van den Broek N. (2014). Life Saving Skills Manual: Essential Obstetric and Newborn Care. Royal College of Obstetricians and Gynaecologists. 1st edition, ISBN-10: 1904752284, ISBN-13: 9781904752288.

Van Lonkhuijzen L, Dijkman A, Van Roosmalen J, Zeeman G, Scherpbier A. (2010). A systematic review of the effectiveness of training in emergency obstetric care in low-resource environments. An International Journal of Obstetrics and Gynaecology, 117(7), 777-787. DOI: 10.1111/j.1471-0528.2010.02561.x.

World Health Organization (2015). Health in 2015: From MDGs to SDGs. Geneva: World Health Organization. Erişim tarihi: 15. 05. 2020, http://www.who.int/gho/publica tions/mdgssdgs/en/.

World Health Organization (2016). Standards for improving quality of maternal and newborn care in health facilities. Geneva: World Health Organization.

World Health Organization (2018). Maternal Mortality Key Facts. Erişim tarihi: 15.05.2020, https://www.who.int/ en/news-room/factsheets/detail/maternal-mortality 